\title{
USO DOS BIOCERÂMICOS NA ENDODONTIA: REVISÃO DE LITERATURA
}

\author{
Glória Maria de Françal \\ Juliana Campos Pinheiro" \\ Everton Freitas de Morais ${ }^{\text {III }}$ \\ Rafaella Bastos Leite IV \\ Carlos Augusto Galvão Barboza \\ Clóvis Stephano Pereira Bueno ${ }^{*}$
}

\section{RESUMO}

O tratamento endodôntico convencional proporciona condições para o organismo curar a doença pulpar e permitir que o dente afetado restabeleça as suas funções estéticas e funcionais. Porém, quando isto não é possível, devido a manutenção de bactérias persistentes no interior do canal radicular, é realizado o retratamento endodôntico. Nesse contexto, este trabalho teve como propósito, através de uma revisão da literatura, apresentar os cimentos biocerâmicos encontrados no mercado (iRoot $\mathrm{BP}{ }^{\circledR}$, EndoSequence ${ }^{\circledR}$, MTA Repair HP Angelus $^{\circledR}$, TotalFill BC sealer $^{\circledR}$ e RetroMTA ${ }^{\circledR}$ ), bem como demonstrar suas aplicações clínicas como material obturador e selador periapical. Assim, foi realizado um levantamento bibliográfico na base de dados do Pubmed, desconsiderando trabalhos de conclusão de curso e artigos publicados antes de 2006, selecionando, assim, 31 artigos para compor a pesquisa. Os biocerâmicos podem ser utilizados como material obturador, por serem de bom escoamento, devido proporcionar baixa viscosidade, apresentar ação antimicrobiana, fácil aplicação e excelente capacidade de adesão a dentina, além de aumentar a resistência à fratura da raiz. Enquanto que, como material selador periapical, eles têm biocompatibilidade, notando-se ausência de inflamação e dor nos casos de sobreobturação, um menor tempo de presa e facilidade de manipulação, quando comparado ao MTA (Agregado de Trióxido Mineral). Contudo, constata-se que, os cimentos biocerâmicos apresentam propriedades promissoras para serem utilizados como material selador no tratamento endodôntico.

PALAVRAS-CHAVE: Restauração Dentária. Reparo. Tratamento Endodôntico. Doutorando em Patologia Oral, Universidade Federal do Rio Grande do Norte, Natal, Rio Grande do
Norte, Brasil.

ORCID: 0000-0002-0483-6601

Doutoranda em Biologia Oral e Biopatologia Experimental, Universidade Federal do Rio Grande do II Norte, Natal, Rio Grande do Norte, Brasil. ORCID ID: 0000-0001-5687-7635

Doutorando em Biologia Oral e Biopatologia Experimental, Universidade Federal do Rio Grande do III Norte, Natal, Rio Grande do Norte, Brasil. ORCID ID: 0000-0002-2173-7672

Professora da Universidade Estadual da Paraíba, Campina Grande, Paraíba, Brasil. Autor Correspon- IV* dente: rrafaella bastos@hotmail.com. ORCID ID: 0000-0002-3304-120X

Professor Associado Universidade Federal do Rio Grande do Norte, Programas de Pós-graduação em Patolo- V gia Oral e em Biologia Estrutural e Funcional, Natal, Rio Grande dỏ Norte, Brasil. ORCID ID: 0000-0003-1979-9919

Professor da Pós-Graduação da Associação Brasileira de Odontologia (ABO - AL), Maceió, VI Alagoas, Brasil.

Submissão: 08/01/2018 Aceito: 05/06/19

DOI: 10.17695/revnevol17n2p45-55 


\section{INTRODUÇÃO}

Os materiais baseados em biocerâmicos têm sido recentemente introduzidos na endodontia, como material de obturação do canal radicular, usado na retrobturação e como cimento reparador. Os biocerâmicos são o resultado da combinação entre o silicato de cálcio e o fosfato de cálcio que são aplicáveis para o uso médico e odontológico. De acordo com os fabricantes, estes materiais apresentam pH alcalino, atividade antibacteriana, radiopacidade e biocompatibilidade. ${ }^{1}$

Como material de preenchimento do canal radicular, os biocerâmicos demonstram grande ligação a dentina, devido a vantagem em formar hidroxiapatita, durante o processo de presa, e criam uma íntima ligação entre a parede dentinária e o cimento, fator importante para reduzir a probabilidade de fratura da raiz. A principal aplicação dos biocerâmicos reside na utilização como cimento reparador no selamento apical de dentes submetidos a cirurgia paraendodôntica, procedimento que tem como finalidade resolver problemas que não puderam ser solucionados pelo tratamento endodôntico convencional, ou quando este não é possível. 2,3,4

O material selador tem por objetivo prevenir a infiltração de microrganismos e seus produtos para dentro dos tecidos periapicais e possibilitar um ambiente propício para a regeneração tecidual. Diferentes materiais obturadores têm sido utilizados em cirurgias paraendodônticas, de acordo com seus principais componentes: amálgama de prata, óxido de zinco e eugenol, hidróxido de cálcio, MTA (Agregado de Trióxido Mineral) e, os mais recentes, os cimentos biocerâmicos. 5

Os biocerâmicos têm mostrado taxas de sucesso de 86,4 a 95,6\%, significativamente maiores do que o amálgama e o MTA, quando utilizadas como materiais de preenchimento retrógrado em cirurgia apical. Entretanto, essas altas taxas não foram atribuídas unicamente ao tipo de material de preenchimento, uma vez que as técnicas cirúrgicas e fatores prognósticos dos dentes podem afetar o resultado do tratamento. 6

Os biocerâmicos têm vantagens tais como: um bom escoamento devido à baixa viscosidade do material, apresentam ação antimicrobiana, fácil manipulação e um menor tempo de presa, permitindo o seu uso como selador apical nas cirurgias paraendodônticas. 4,7 Porém, a sua desvantagem reside no fato de ser de difícil remoção nos casos de retratamento. $8,9,10,11$

O presente estudo tem a finalidade de pesquisar na literatura atual os tipos de biocerâmicos existentes no mercado, elucidar as suas vantagens e desvantagens, seu mecanismo de ação, formas de utilização, propriedades clínicas e suas aplicações comparando-os com outros materiais usados na obturação dos canais radiculares e seladores apicais.

\section{MATERIAL E MÉTODOS}

Foi realizado um levantamento bibliográfico na plataforma Pubmed, utilizando os seguintes unitermos correlacionados: bioceramic sealers, bioceramics in endodontics e bioceramic as root-end filling material. Foi adotado como critério de seleção do material bibliográfico, todos os artigos originais, revisõese literatura e relatos de caso, publicados 
entre os anos 2006 e 2019, que apareceram na busca baseada nos descritores acima. Entretanto, utilizou-se como critério de exclusão trabalhos, evidenciados durante a busca, que foram publicados anteriormente a data limite

\section{RESULTADOS E DICUSSÃO}

O MTA (Agregado de Trióxido Mineral) tem algumas limitações, incluindo descoloração dos dentes, manipulação difícil e tempo de ajuste prolongado. As biocerâmicas foram recentemente desenvolvidas para melhorar as propriedades do MTA, tais como o líquido Biodentine que foi adicionado ao cloreto de cálcio para diminuir o tempo de presa (12 minutos) e o óxido de zircônio, como radiopacificador e para reduzir a incidência de descoloração. Outro material a base de silicato de cálcio é o TotalFill (TotalFill BC RRM; FKG, Suíça), em que o fosfato de cálcio monobásico é um agente que aumenta a formação de hidroxiapatita. ${ }^{12}$

$\mathrm{Na}$ Endodontia, os materiais biocerâmicos apresentam-se principalmente como cimento reparador e como cimento endodôntico. 13,14,15,16 Os biocerâmicos têm propriedades reparadoras e podem ser usadas de duas formas: a resina Flow, que serve como cimento de obturação dispensável em seringa, e o putty que vem pré-misturado e tem utilidade no selamento de perfurações, cirurgias e tampões. Esta é uma grande ajuda, não apenas possibilitando a obtenção de uma mistura adequada, bem como na forma de utilização. 4

Os biocerâmicos apresentam elevada biocompatibilidade, alta resistência e não contraem. A sua força compressiva é de 50-70 Mpa, o que é similar a outros materiais, a exemplos do ProRoot MTA ${ }^{\circledR}$ (Dentsply ${ }^{\circledR}$ ) e do BioAggregate ${ }^{\circledR}$ (Diadent ${ }^{\circledR}$ ). Contudo, o que o diferencia é o tamanho das suas partículas que permite aplicação através de uma seringa. A utilização
VOLUME 17 - NÚMERO 2 - AGO/2019 ISSN ELETRÔNICO 2317-7160 (ano 2006) e trabalhos de conclusão de curso (dissertações). Desse modo, de 33 artigos evidenciados na busca, utilizaram-se 31 trabalhos para composição final deste Artigo de Revisão.

da seringa tem vantagens, pois elimina a necessidade de espatulação e a sua mistura. Considerando seu tamanho inferior a $2 \mu$, o biocerâmicos pode ser dispensado por uma ponta capilar que permite que o material de $2 \mu$, pré misturado, seja colocado na zona de reparação radicular. Além disso, as pontas capilares são flexíveis e permitem o melhor acesso ao canal radicular, sendo assim, o cimento é inserido cuidadosamente através da ponta capilar, a qual, não deve ultrapassar o terço coronal porque o material suficiente será levado ao comprimento de trabalho pelo cone principal. ${ }^{14,17,18}$

O escoamento de um cimento é definido como a consistência desse elemento que confere capacidade de penetrar nas estreitas irregularidades da dentina o que constitui um importante fator na obturação de canais laterais, acessórios e istmos. ${ }^{19} \mathrm{O}$ escoamento, proposto pela ISO 6876/2001, preconiza o volume de cimento igual a 0,05 $\pm 0,005 \mathrm{ml}$ e o diâmetro do disco formado pelo cimento comprimido não deve ser menor do que $20 \mathrm{~mm}$.

A espessura do cimento é avaliada a partir de sua tendência de contrair e se dissolver com o tempo. Cimentos com menores espessuras são preferidos em relação aos de maiores espessuras, pois esses, a longo prazo, melhoram a habilidade de selamento dos materiais utilizados, tanto para a obturação dos canais radiculares, quanto em retropreparozo. Entretanto, um cimento que apresente alto escoamento pode facilitar o extravasamento do material para a região periapical e cuidados 
devem ser tomados durante a obturação endodôntica para se evitar uma sobreobturação. 21,22

Haddad et al. 5 avaliaram e compararam a espessura e a adaptação interface de cimentos biocerâmicos (Sankin Apatite III, MTA Fillapex ${ }^{\circledR}$, EndoSequence ${ }^{\circledR} B C$ ) na dentina radicular contra o cimento AH Plus ${ }^{\circledR}$. Sessenta pré-molares de raiz única extraídos foram preparados e igualmente divididos em quatro grupos. Os aferidores foram marcados com 0,1\% de corante fluorescente Rodamina B. As raízes foram dissecadas ao longo do plano transversal a $1 \mathrm{~mm}$ (apical), $3 \mathrm{~mm}$ (médio), e níveis de $6 \mathrm{~mm}$ (coronal). Foi avaliada toda a relação de selamento da área do canal. A Porcentagem da região contendo gap na circunferência do canal foi calculada usando um microscópio confocal a laser. A espessura do cimento foi significativamente maior nos níveis apical e médio, quando comparada ao nível coronal. Enquanto o nível coronal apresentou significativamente menos gaps na interface, o Endosequence BC Sealer apresentou espessura significativamente maior em comparação com MTA Fillapex e o H Plus.

O MTA foi introduzido especificamente para a obturação apical e o reparo de perfurações e é considerado um padrão "Ouro" nos materiais retrobturadores. Demonstra a capacidade de vedação superior e biocompatibilidade, em comparação com outros materiais, porque tem a capacidade de liberar íons cálcio e induzir a formação de hidroxiapatita. Já os odontoblastos se ligam ao cimento aplicado, levando a formação de um novo tecido duro. 23,24,25 Contudo, características pobres de manipulação, frouxidão inicial e tempo de presa lenta fazem do MTA de difícil uso.

O fabricante de um novo material biocerâmico, Endosequence BC Root Repair (BCRR), propõe propriedades físicas e mecânicas semelhantes aquelas vistas no MTA, mas com manuseio superior, uma vez que, a infiltração continua a ser uma prioridade ao avaliar um novo material de preenchimento retrógrado. Com base nesta premissa, o objetivo do estudo de Nair et al. ${ }^{26}$ foi comparar, in vitro, a microinfiltração de material BCRR com MTA branco, como material obturador retrógrado, utilizando um modelo de infiltração bacteriana. Quarenta dentes unirradiculares foram instrumentados, obturados com guta-percha, o término da raiz seccionado e retrobturados com 2 materiais diferentes: ProRoot MTA branco (WMTA) $(n=15)$ e BCRR ( $n=15)$. Espécimes que não receberam qualquer preenchimento $(\mathrm{N}=10)$ foram usados como controles. Todos os grupos receberam $\mathrm{E}$. faecalis em um reservatório criado para o preenchimento radicular e a presença de infiltração foi avaliada pela contagem das unidades formadoras de colônias a partir de cada espécime. Foi observado que não houve diferença significativa na infiltração entre os 2 grupos experimentais, mas uma significativa diferença em relação ao controle $(P \leq$ $0,05)$. Este estudo sugere que BCRR é equivalente em vedação a capacidade do MTA bran$\mathrm{co}$, quando usado como material selador apical, in vitro.

Candeiro et al. ${ }^{1}$ compararam as características do cimento endodôntico biocerâmico, Endosequence BC sealer, em relação ao cimento AH Plus. A citotoxicidade e genotoxicidade foram analisadas nos fibroblastos gengivais humanos, submetidos a cultura de células e condicionados por cimentos. Utilizando o ensaio de redução MTT e o teste de formação de micronúcleos (MNT) e a viabilidade das células foram mensuradas em 1, 3, 5 e 7 dias. Para a análise do efeito antimicrobiano, utilizou cepas de Enterococcus faecalis em ambos os testes por difusão em ágar (ADT) e um teste de contato direto (DCT). As zonas de inibição no ADT foram mensuradas após $48 \mathrm{~h}$ e a contagem das unidades formadoras de colônias no DCT depois de 1, 24, 72 e 168h. Observou-se que as culturas submetidas ao Endosequence BC sealer obtiveram maior número de células viáveis e menor 
formação de micronúcleos que as submetidas ao AHplus. Em relação aos testes antimicrobianos em contato direto (teste DCT), o AH Plus eliminou completamente o Enterococcus faecalis em $1 \mathrm{~h}$, enquanto que $\mathrm{o}$ Endosequence $B C$ sealer apresentou melhor efetividade antimicrobiana, após $24 \mathrm{~h}$ do contato direto. Logo, o Endosequence $B C$ sealer exibiu significativamente menores zonas de inibição do que o cimento AHplus. Pode-se concluir que o cimento biocerâmico teve menor citotoxicidade e genotoxicidade e similar efeito antibacteriano contra o E. faecalis em comparação ao cimento $\mathrm{AH}$ Plus.

O dispensador biocerâmico pode ser utilizado no canal radicular com a utilização de uma seringa pré-misturada. Assim, a mistura do cimento não é necessária o que evita problemas, tais como mistura não homogênea e material insuficiente. Além disso, a condensação hidráulica sincronizada é característica dos cimentos biocerâmicos, isto leva a formação de uma verdadeira ligação entre a parede do canal radicular com o cone principal. Entretanto, o ajuste necessário do cone principal deve ser obtido através de uma instrumentação cuidadosa e de conicidade adequada. Estes requisitos promovem excelentes qualidades hidráulicas e por essa razão não é necessário grandes quantidades do cimento selador. $O$ que se pode alcançar com essa técnica é uma ligação química a parede do canal, como resultado da hidroxiapatita, que é criada durante a reação de solidificação do material biocerâmico e também temos uma ligação química entre o cimento biocerâmico e os cones de guta-percha. A vantagem desta técnica é a sua simplicidade, a sua rapidez e os seus resultados. ${ }^{2}$

A cirurgia paraendodôntica é um procedimento que tem como finalidade resolver problemas que não puderam ser solucionados pelo tratamento endodôntico convencional, ou quando este não é possível. A sua área de atuação, o paraendodonto, compreende a região
VOLUME 17 - NÚMERO 2 - AG0/2019 ISSN ELETRÔNICO 2317-7160 periapical e regiões limítrofes, para as quais podem se estender as complicações endodônticas $^{3}$.

O motivo principal para se realizar a cirurgia é o fator microbiológico, que é apontado como a maior causa de falhas do tratamento endodôntico convencional, sendo recomendada em casos de infecções periapicais persistentes, com cronicidade e extensa área radiolúcida apical, necessidade de biópsia, defeitos endo-periodontais, perfuração e traumatismos com fratura do terço apical, complicações anatômicas permitindo a vantagem da visualização do término dos canais, problemas iatrogênicos, problemas durante o tratamento e falhas em tratamento endodôntico previamente realizado. 4

O conhecimento da sequência cirúrgica se faz necessário para a sua realização, que envolve a anestesia, incisão, divulsão, osteotomia, curetagem, secagem, radiografia transoperatória e sutura. As incisões poderão ser realizadas em retalhos dos tipos: retangular, em concha, trapezoidal ou semilunar e as modalidades operatórias poderão ser apicectomia, cirurgia com obturação simultânea, obturação retrógrada e retroinstrumentação com retrobturação (Figura 1$).{ }^{26}$

Tão importante quanto a confecção do retropreparo é a escolha de um adequado material selador, o qual deverá aderir as paredes cavitárias, promovendo o selamento do sistema de canais radiculares, ser biocompatível, atóxico, não carcinogênico, não ser reabsorvível, possuir boa estabilidade dimensional, ser radiopaco e insensível a umidade4. Além de oferecer facilidade de manipulação e inserção ${ }^{12}$. 0 componente de fosfato de cálcio nos biocerâmicos não é tóxica e tem a vantagem de se tornar funcional integrando com o osso sem encapsulamento fibroso. Esse componente promove a extensão de osso em áreas que este ocuparia pela formação de uma matriz adequada para a deposição de novo osso. Fosfato dicálcico inclui 


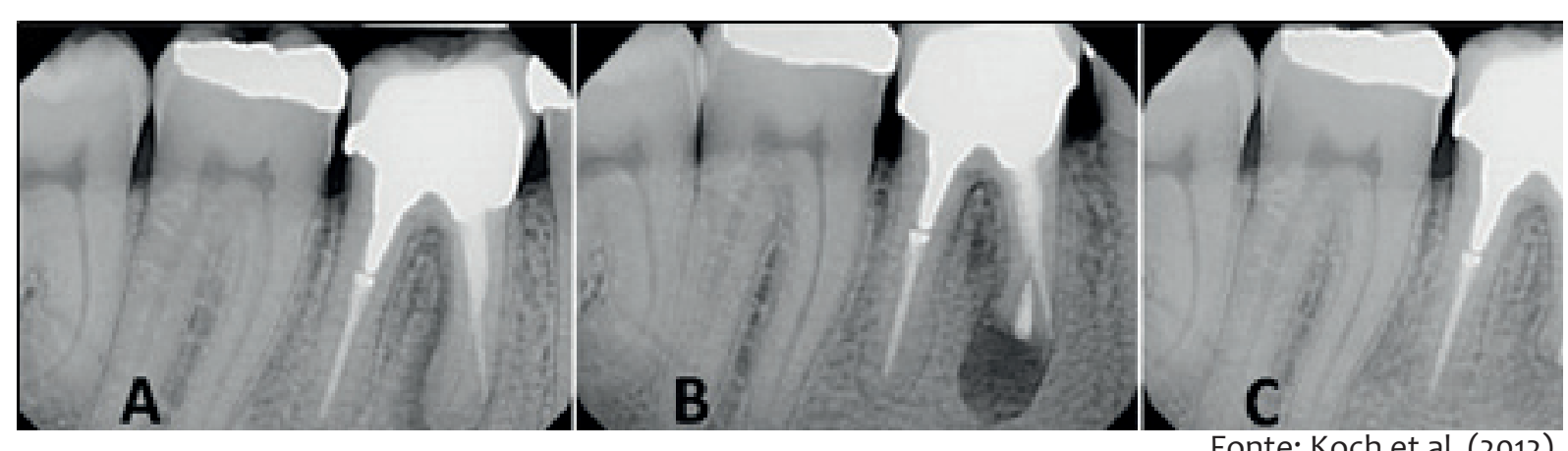

FIGURA 1. Primeiro molar inferior com lesão apical na raiz mesial (A), após cirurgia periapical (apicectomia) com obturação retrógrada com cimento biocerâmico (B) e a regeneração da mesma lesão após 6 meses (C)

tanto fosfato ß-tricálcico e hidroxiapatita. Esses juntos, devido as suas características, Um outro ponto importante a ser destacado se refere ao elucidado na questão 10 , em que se obteve $86,7 \%$ da média de acerto entre os entrevistados e que se tratava de qual seria a melhor maneira de prevenir a transmissão, consistindo em evitar o contato com os fluidos corporais do paciente infectado.

Quanto ao manejo dos pacientes e 24 permitem o controle das suas propriedades. ${ }^{11}$
Shinbori ${ }^{4}$, no estudo Clinical Outcome of Endodontic Microsurgery That Uses EndoSequence BC Root Repair Material as the Root-end Filling Material, analisou prontuários e radiografias periapicais de pacientes submetidos a microcirurgia endodôntica, realizada pelo mesmo endodontista, que utilizou o EndoSequence $\mathrm{BC}$ root repair como um material de selamento apical. Com base nos achados clínicos e radiográficos, os casos cicatrizados e em processo de cicatrização foram agrupados e consi-
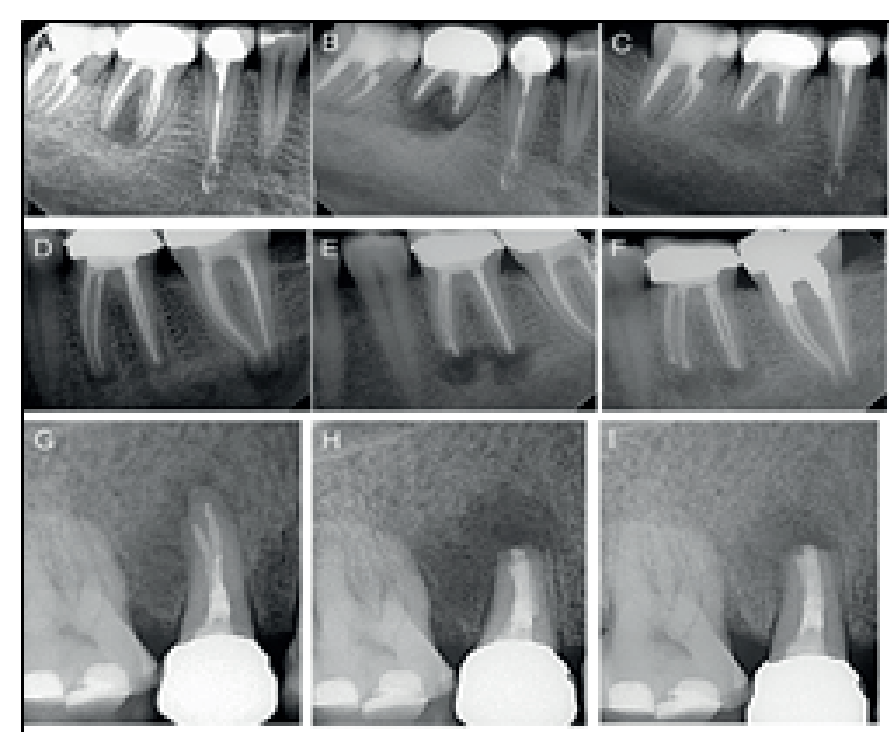

FIGURA 2. Representação das radiografias periapicais nas categorias de sucesso e insucesso após cirurgia paraendodôntica e selamento com Endosequence BC Root Repair. (A-C) Exemplo mostrando completa cicatrização. (D-F) Exemplo mostran-

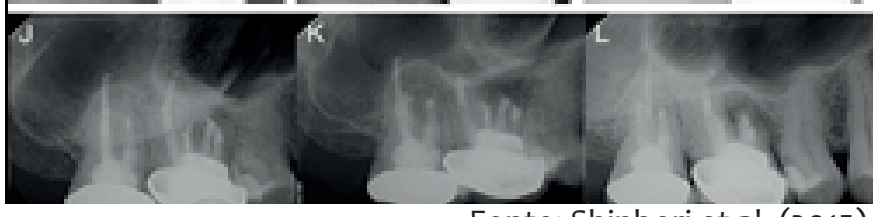
do cicatrização incompleta. (F) um ano de acompanhamento radiográfico mostrando redução da radioluscência periapical, caso de sucesso. (G-L) Exemplo mostrando cicatrização insatisfatória, casos de insucesso. 


\section{revista de
ciências da saúde ESPERANÇA}

derados como sucesso e os casos não cicatrizados foram considerados como fracasso. Dos 113 casos, 104 foram classificados como sucesso, com um índice de $92 \%$. Dos 9 dentes que foram classificados como fracasso, 5 eram fracassos radiográficos (Figura 2), e 4 eram dentes clinicamente sintomáticos com dor a percussão, ou palpação, ou ainda tinha fístula presente. Assim, sugere-se que o Endosequence $B C$ root repair é um material selador apical disponível que pode ser usado na cirurgia paraendodôntica de forma eficiente.

Kim et al. ${ }^{27}$ avaliaram a presença de material de preenchimento residual no retratamento dos canais radiculares usando tomografia micro-computadorizada (micro-CT). Para tanto, foram utilizados 21 dentes unirradiculares, 21 multirradiculares e 15 em forma de C, preparados e distribuídos aleatoriamente em três subgrupos para obturação com guta-percha e três selantes diferentes (EndoSeal MTA, EndoSequence $B C$ sealer e AH Plus). Após 10 dias, o material de preenchimento foi removido e os canais radiculares instrumentados em tamanho acima do comprimento de trabalho apical anterior. A porcentagem de material de preenchimento restante após o retratamento foi calculada nos terços coronal, médio e apical. Evidenciou-se que os selantes testados não apresentaram diferenças significativas na porcentagem de material de preenchimento em dentes de raiz única e dupla. Enquanto que, para raízes em forma de $\mathrm{C}$ o material de preenchimento residual do AH Plus e EndoSeal MTA foi maior do que em raízes simples ou duplas $(p<0,05)$. Já o selante $B C$ foi semelhante em todos os tipos de raízes. Dentro das limitações deste estudo, uma grande quantidade de EndoSeal MTA permaneceu após retratamento, enquanto que o EndoSequence $B C$ sealer foi o cimento que menos apresentou resíduos.

Candeiro et al. ${ }^{1}$ concluíram que o Endosequence $B C$ sealer apresentava radiopacidade inferior ao cimento $\mathrm{AH}$ plus, devido a presença
VOLUME 17 - NÚMERO 2 - AG0/2019 ISSN ELETRÔNICO 2317-7160 de um único radiopacificador (óxido de zircônio) corroborando com o estudo de Souza et al.18, em que o biocerâmico RetroMTA ${ }^{\circledR}$ também apresentou radiopacidade inferior ao ProRoot MTA ${ }^{\circledR}$, com o constituinte de radiopacificador, o óxido de zircônio, semelhante ao encontrado no Endosequence BC sealer. Logo, os biocerâmicos têm menores índices de radiopacidade, quando comparados a esses materiais, e isto é devido a composição do $\mathrm{AH}$ plus que tem dois agentes radiopacificadores (o óxido de zircônio e tungstato de cálcio) e o maior índice de radiopacidade do óxido de bismuto, presente no ProRoot MTA.

Com relação ao escoamento, Candeiro et al. $^{1}$ confirmaram que $\mathrm{O}$ Endosequence $\mathrm{BC}$ sealer apresenta fluxo de escoamento maior do que o $\mathrm{AH}$ plus corroborando com o estudo feito por Haddad 5 , em que, verificaram que além do Endosequence $B C$ sealer ter um fluxo de escoamento maior, a sua espessura também se apresenta, significantemente, maior do que o AHplus. Além disso, a espessura do cimento se mostrou menor no terço coronal do que nos terços médio e apical, provavelmente, devido ao acúmulo do cimento nos terços inferiores e explica o porquê do nível coronal ter menos gaps na interface cimento-dentina em comparação com os níveis apical e médio.

Quanto às propriedades de adesão e infiltração marginal, Nair et al. ${ }^{26}$ verificaram que o biocerâmico Endosequence Root Repair é equivalente em vedação a capacidade do MTA branco quando usado como material selador apical. Resultados similares, foram encontrados por Leal et al. ${ }^{28}$, em que o iRoot BP tinha uma habilidade similar a do MTA branco na prevenção da entrada de glicose como um material de reparação. Porém, os resultados encontrados por Shokouhinejad et al. ${ }^{29}$ foram negativos para o Endosequence Root Repair do tipo pasta o qual apresentou mais gaps nas secções longitudinais, o que colabora para a infiltração marginal. Uzunoglu et al. ${ }^{9}$ não verificaram 
revista de ${ }^{\text {ciências }} \mathbf{O V}$

da saúde ESPERANÇA

diferenças no potencial de adesão dos biocerâmicos a dentina radicular, independentemente, da associação com $\mathrm{NaOCL}$, CHX ou solução salina, observando-se a adesão mais alta para grupos de EDTA, quando cada cimento foi avaliado isoladamente. Em contraste, outros autores, encontraram resultados diferentes, verificando que a irrigação com $\mathrm{CHX}$ reduz a resistência de união do Endosequence $\mathrm{BC}$ sealer. ${ }^{3}$ Entretanto, ambos os estudos afirmaram que a força de ligação dos cimentos endodônticos é influenciada por suas propriedades e diversos tratamentos de superfície da dentina.

Com relação ao efeito antimicrobiano, Lodi et al. 3 concluíram que os cimentos Endosequences Root Repairs dos tipos putty, pasta e o MTA têm eficácia antibacteriana similar contra cepas de E. faecalis. Todavia, Candeiro et al. ${ }^{1}$ relataram que o Endosequence $\mathrm{BC}$ sealer apresenta melhor efetividade antimicrobiana, após $24 \mathrm{~h}$ do contato direto. Logo, o Endosequence BC sealer, quando comparado ao MTA, possui similar efeito antibacteriano, porém exibe menores zonas de inibição do que o cimento AHplus após 1 h da inserção.

Damas et al. ${ }^{15}$ concluíram que o Endosequence Root Repair demonstrou similares níveis de citotoxicidade, nos fibroblastos, em relação aos cimentos MTA testados (ProRoot e MTA angelus). Corroboram com outros autores que comprovaram a não inibição dos materiais e a proliferação de fibroblastos do ligamento periodontal e osteoblastos2. Observou-se, também, que culturas submetidas ao Endosequence $B C$ sealer tiveram maior número de células viáveis e menor formação de micronúcleos comparadas ao AH plus. ${ }^{1}$ Enquanto que o MTA e o Endosequence Root Repair se apresentam biocompatíveis e promovem a proliferação e sobrevivência das células. ${ }^{7}$

Consequentemente, estes materiais podem ser recomendados como seladores retrógrados na prática endodôntica. Entretanto, Siqueira et al. ${ }^{11}$ observaram que o Endosequen-
VOLUME 17 - NÚMERO 2 - AGO/2019 ISSN ELETRÔNICO 2317-7160 ce Root Repair reduziu a bioatividade e a atividade da fosfatase alcalina nos osteoblastos em todos os períodos de tempo e Güven et al.30 concluíram que o iRoot SP e AH Plus Jet podem promover uma melhor adesão a células embrionárias humanas (stem cells). Isto ocorre porque os cimentos baseados em silicato de cálcio estimulam a adesão celular e a diferenciação odontoblástica das células humanas da polpa dental.

Com relação a resistência a fratura radicular, Ghoneim et al. ${ }^{2}$ inferiram que o cimento biocerâmico (iRoot SP), associado a cones de guta-percha, aumentou a resistência à fratura das raízes com o tratamento endodôntico. Corroborando com esses achados, Topçuoglu et al. ${ }^{31}$ propuseram que a força requerida para fratura nos dentes foram maiores com o uso dos seladores Endosequence $B C$ sealer e AHplus do que com o MTA. Semelhantemente, Nair et al. ${ }^{26}$, usando o Endosequence BC, verificaram que a força de fratura requerida foi maior do que o controle positivo (dentes instrumentados sem preenchimento).

Quanto ao retratamento, Hess et al. ${ }^{8}$ relataram que as técnicas e os solventes de retratamento convencionais não são eficazes em remover totalmente os biocerâmicos. Resultados semelhantes foram encontrados por Agrafioti et al. ${ }^{10}$, o qual, recomendaram o uso dos biocerâmicos nos canais radiculares com anatomia simples. Porém, $\mathrm{Kim}^{27}$ constatou que a utilização do Endosequence $B C$ sealer promove menor quantidade de material de preenchimento residual nos terços coronal, médio e apical em dentes unirradiculares, multirradiculares e em canais em $C$, quando comparados ao uso dos cimentos EndoSeal MTA e AH Plus.

Os biocerâmicos devem ser utilizados como seladores apicais nas cirurgias paraendodônticas. Nesse contexto, Shinbori et al. 4 defenderam que o Endosequence BC root Repair é um material selador apical disponível que pode ser usado, de forma eficiente, na cirurgia 
paraendodôntica. Corroborando com Chen et al. ${ }^{7}$ que comprovaram ser o Endosequence Root Repair um material biocompatível e com boa habilidade seladora.

Contudo, biocerâmicos são cimentos endodônticos de grande sucesso e têm várias vantagens, tais como a melhoria da biocompatibilidade, capacidade de selamen-

\section{CONSIDERAÇÕES FINAIS}

Os cimentos endodônticos foram idealizados e produzidos como material de preenchimento do canal e como selador apical em cirurgias paraendodônticas. A escolha de um bom selador é uma etapa importante do procedimento endodôntico. Nesse contexto, os biocerâmicos têm se mostrado um material promissor, demonstrando algumas vantagens: aumentam a força requerida para a fratura da raiz; apresenta boa adesão as paredes dentinárias; não apresenta toxicidade; são biocompatíveis e de fácil inserção.

As propriedades físico-químicas de adesão, radiopacidade, escoamento, atividade antibacteriana, fácil aplicação e menor to, propriedades antibacterianas,facilidade de aplicação e um aumento na resistência da raiz, após a obturação. A extrema biocompatibilidade do biocerâmico também pode ser observada nos casos de sobreobturação, quando há ausência de inflamação e dor, ou dor mínima após o extravasamento do excesso do cimento durante a obturação. ${ }^{12}$ tempo de presa, demonstraram-se favoráveis para um material de obturação radicular baseado nos biocerâmicos. No entanto, os materiais biocerâmicos têm sido de difícil remoção em casos de retratamento, devido a formação da hidroxiapatita e a maior adesão a parede dentinária, sendo necessário mais tempo para a sua remoção e o emprego de técnicas não convencionais. Em virtude disto, os biocerâmicos deveriam ser utilizados como materiais seladores ao invés de material de preenchimento completo do canal e poderiam ser usados com um material central, pois facilitaria a retratabilidade nos casos em que o retratamento está indicado.

\title{
USE OF BIOCHEMICALS IN ENDODONTIA: LITERATURE REVIEW
}

\begin{abstract}
Conventional endodontic treatment aims to provide conditions for the body to heal pulpal disease and to allow the affected tooth to restore its aesthetic and functional functions. However, when this is not possible, due to the persistence of continuing bacteria inside the root canal, endodontic retreatment is performed. The objective of this work was to present the bioceramic cement found in the market (iRoot $B P{ }^{\circledR}$, EndoSequence ${ }^{\circledR}$, MTA Repair HP Angelus $^{\circledR}$, TotalFill BC sealer $^{\circledR}$, and RetroMTA ${ }^{\circledR}$ ). sealant and periapical sealer. Methodology: For its preparation, a bibliographic survey was carried out in the Pubmed database of the 33 articles found, 31 were selected. Literature Review: Bioceramics can be used as a sealing material because it has a good flow due to the low viscosity of the material, antimicrobial action, easy application, increased root fracture resistance, dentin adhesion capacity and periapical sealant material because has biocompatibility, in which there is absence of inflammation and pain in the cases of sobreobturação, a smaller prey time and ease of manipulation when compared to the MTA.
\end{abstract}

KEYWORDS: Filling. Repair. Endodontics. 


\section{REFERÊNCIAS}

1. Candeiro GT, Correia FC, Duarte MA, Ribeiro-siqueira DC, Gavini G. Evaluation of radiopacity, $\mathrm{pH}$, release of calcium ions and flow of a bioceramic root canal sealer. International Endododontic Journal 2012; 38(6): 842-45.

2. Ghoneim AG, Lutfy RA, Sabet NE, Fayyad DM. Resistance to Fracture of Roots Obturated with Novel Canal-filling Systems. J Endod 2011;37(11):1590-92.

3. Lodi LM, Poleto S, Soares RG, Irala LED, Salles AA, Limongi O. Cirurgia paraendodôntica: relato de caso clínico Paraendodontic surgery: case report. Revista sul-brasileira de Odontologia. 2008; RSBO. 5(3).

4. Shinbori N, Grama AM, Patel Y, Woodmansey $\mathrm{K}$, He J. Clinical Outcome of Endodontic Microsurgery That Uses EndoSequence BC Root Repair Material as the Root-end Filling Material. J Endod 2015; 41:607-12.

5. Haddad AA, Kasim NHA, Aziz ZACA. Interfacial adaptation and thickness of bioceramic-based root canal sealers. Dental Materials Journal 2015; 34 (4):516-521.

6. Abusrewil SM, McLean W, Scott JA. The use of Bioceramics as root-end filling materials in periradicular surgery: A literature review. Saudi Dental Journal 2018; 30 (4): 273-82

7.Chen I, Karabucak B, Han-guowang C, Koyama E, Kohli MR, Nah HD, Syngcuk KIMS. Healing after Root-end Microsurgery by Using Mineral Trioxide Aggregate and a New Calcium Silicate-based Bioceramic Material as Root-end Filling Materials in Dogs. J Endod 2015; 41(3):389-99.

8. Hess D, Solomon E, Spears R. Retreatability of a Bioceramic Root Canal Sealing Material. J Endod 2011; 37:1547-49.

9. Uzunoglu E, Yilmaz Z, Sungur DD, Altundasar E. Retreatability of Root Canals Obturated Using Gutta-Percha with Bioceramic, MTA and Resin-Based Sealers. Iranian Endodontic Journal 2015;10(2): 93-98.

10. Agrafioti A, Koursoumis AD, Kontakiotis EG. Re-establishing apical patency after obturation with Gutta-percha and two novel calcium silicate-based sealers. Eur J Dent 2015; 9:457-61.

11. Siqueira Zuolo A, Zuolo ML, Bueno CES, Chu R, Cunha RS. Evaluation of the Efficacy of TRUShape and Reciproc File Systems in the Removal of Root Filling Material: An Ex Vivo Micro Computed Tomographic Study. J Endod 2016; 42:315-19.

12. Lertmalapong $P$, Jantarat J, Srisatjaluk RL, Komoltri C. Bacterial leakage and marginal adaptation of various bioceramics as apical plug in open apex model. Journal of Investigative and Clinical Dentistry 2019;10 (1):123-71.

13. Tsumita $M$, Kokubo $\mathrm{Y}$, Vult-von-steyern $\mathrm{P}$, Fukushima S. Effect of framework shape on the fracture strength of implant-supported all-ceramic fixed partial dentures in the molar region. $J$ Prosthodont. 2008; 17(4):274-85.

14. Koch KA, Brave DG, Nasseh AA. Bioceramic technology: closing the endo-restorative circle, part I. Dent. Today. 2010; 29(2): 100-5.

15. Damas BA, Wheater MA, Bringas JS, Hoen MM. Cytotoxicity comparison of mineral trioxide aggregates and EndoSequence bioceramic root repair materials. Journal of Endodontics 2011; 37:372-75. 
16. Lima et al. Cimentos biocerâmicos em odontologia: revisão de literatura. RFO, Passo Fundo 2017; 22 (2):248-254.

17. Malhotra S, Hegde M, Shetty C. Bioceramic technology in endodontics. British Journal of Medicine \& Medical Research. 2014; 4(12): 24462454.

18. Souza LC. et al. Analysis of radiopacity, pH and cytotoxicity of a new bioceramic material. J. Appl. Oral Sci 2015; 23 (4):383-389.

19. Grossman LI. Physical propertiesof root canal cements. J Endod 1976; 2(6):166-75.

20. De-deus G, Coutinho-filho T, Reis C, Murad C, Paciornik S. Polymicrobial leakage of four root canal sealers at two diferente thiknesses. Journal of Endodontics 2006; 32: 998-1001.

21. Loushine BA, Bryan TE, Looney SW, Gillen BM, Loushine RJ, Weller N, Pashley DH, Tay FR. Setting properties and cytotoxicity evaluation of a premixed bioceramic root canal icisealer. Journal of Endodontics 2011; 37: 673-7.

22. Zoufan K, Jiang J, Komabayashi T, Wang Y, Safavi KE, Zhu Q. Citotoxicity evaluation of Gutta Flow and EndoSequence BC sealers. Oral Surg. Oral. Med. Oral. Pathol. Oral Radiol. Endod 2011; 112:657-61.

23. Jacobovitz M, Pappen FG, Lima RKP. Obturaçao com MTA associado à cirurgia paraendodôntica no retratamento de reabsorção radicular apical externa- relato de caso. RBSO Revista Sul-brasileira de Odontologia. 2008; 6(2):1-10.

24. Menezes R, Bramante CM, Garcia RB, Letra A, Carvalho VG, Carneiro E, Brunini S, Oliveira RC, Canova GC, Moraes FG. Microscopic analysis of dog dental pulp after pulpotomy and pulp protection with mineral trioxide aggregate and white Portland cement. J Appl Oral Sci. 2004;
12(2):104-7.

25.Tomson PL, Grover LM, Lumley PJ, Sloan AJ, Smith AJ, Cooper PR. Dissolution of bio-active dentine matrix components by mineral trioxide aggregate. J Dent. 2007; 35(8): 636-42.

26. Nair U, Ghattas S, Saber M, Natera M, Walker C, Pileggi RA. comparative evaluation of the sealing ability of 2 root-end filling materials: an in vitro leakage study using Enterococcus faecalis. Oral Surg Oral Med Oral Pathol Oral Radiol Endod 2011; 112:74-77.

27. Kim K, Kim DV, Kim S, Yang S. A micro-computed tomographic study of remaining filling materials of two bioceramic sealers and epoxy resin sealer after retreatment. Restorative Dentistry \& Endodontics 2019; 44(2): e 18.

28. Leal F, De-deus G, Brandao C, Luna A, Souza E, FideL S. Similar Sealability Between Bioceramic Putty Ready-To-Use Repair Cement and White MTA. Brazilian Dental Journal 2013; 24(4): 362-366.

29. Shokouhinejad N, Hoseini A, Gorjestani H, Shamshiri AR. The Effect of Different Irrigation Protocols for Smear Layer Removal on Bond Strength of a New Bioceramic Sealer. Iranian Endodontic Journal 2013; 8(1):10-13.

30. Güven EP, Yalvaç ME, Kayahan MB, Sahin F, Sunay H, Bayirli G. Human tooth germ stem cell response to calciumsilicate based endodontic cements. Journal of Applied Oral Science 2013; 21(4):351-7.

31. Topçuoglu HS, Tuncay Ö, Karatas E, Arslan $\mathrm{H}$, Yeter K. In Vitro Fracture Resistance of Roots Obturated with Epoxy Resin-based, Mineral Trioxide Aggregate-based, and Bioceramic Root Canal Sealers. Journal of Endodontics 2013; 39 (12):1630-1633. 